interesting off-shoot of this, being investigated by one of these professors, is the effect of instruction where the professor develops and displays his own personal brand of theatrics in the classroom.

Television could conceivably play a greater part in expansion of these trends: the rise of certificate courses, greater number of middle-aged students (parents, if you will), and greater number of courses offered at night.

9. OUT-OF-DOORS INSTRUCTION continues to boom. A most visible trend. Americans turned out in millions last summer for informal outdoor education in the arts: music, drama, dance, and musical comedy. U.S. News and World Report in its July 7, 1975 issue reports: "A major reason for the attendance boom, according to many artists, is a widespread desire for 'escape' from current economic problems." Until the 1960 s the performing arts generally took the summer months off, but not so today as emerging summer audiences become progressively younger and more enthusiastic.

How important is this shift in teaching methodologies from standard lecture-and-test to innovative new methods based on building interest, and to new mediums and surroundings? It is important because the quality and speed of social-politicalgrowth in the U.S. during the last twenty-five years of the 20th century will be determined by whatever impact these methodologies, tools, and techniques have on millions of today's Americans. Young Americans only? No. Consider the fact that one large Midwestern city's population has an education level of only 12.1 years. Rapidly evolving new teaching methodologies are for today's adults as well.

Dr. Glenn A. Olds, Kent State University's president, summed up the dawning social revolution on education during a June, 1975, Xavier University interview: these and other changes will point education in the direction it "should take if it is to lead, not stumble, into the future."

\section{NOTES AND REFERENCES}

\footnotetext{
${ }^{1}$ Mel Helitzer, The Youth Market, Media Books, Inc., New York, NY, 1970, pg. 67.
}

\title{
TEACHING-COMMUNICATION METHODOLOGIES IN THE MEDICAL PROFESSION
}

\author{
H. W. Hildebrant \\ The University of Michigan
}

The medical profession is labor intensive. If one accepts that generalization, it follows that many hospital personnel are being taught and asked to update their specialties. And what makes good medical teaching and training a necessity is that the students will often deal with life and death matters. We in the social sciences and humanities might stumble once in a while, but in medicine there is little chance for error.

Our goal, therefore, was to look at five medical publications which might discuss teaching methodologies applicable to other disciplines: Hospitals; American Journal of Nursing; Nursing Outlook; Nursing Research; and the Journal of Nursing Education. In the main the last two years were viewed in order to locate the more recent, innovative teaching techniques.

We will note ten ideas on teaching methodology; suggest specific involvement of business communi- cators; and include a brief bibliography.

\section{IDEAS ON TEACHING METHODOLOGIES}

An opening statement must be made: the medical profession operates in an environment where both the spirit and the body are tended, where communication, either oral or written, must be at once humane and clear. Concern with teaching, therefore, is fervent and sincere.

The majority of teaching methodologies mirrored the conventional, the traditional, the usual, the accepted. Articles on the lecture, the discussion method, grading, outlining, use of visual aids, role playing, case studies, and goal setting predominated. The following ten methods are a bit out of the ordinary and could be used by others. Let me describe each briefly: 


\section{Protocols}

The teaching concept behind this term builds on the usual definition of a procedure or outline to be followed in connection with a given assignment or action to be taken. Such a document has the following characteristics:

-it is an unambiguous statement which suggests a step by step progression in the handling of an event.

-it predefines the actions to be followed in pursuing a given assignment.

-it provides the basis for evaluation, determining whether the user of the protocol followed the written steps precisely in completing the assignment.

-it is useful in working with untrained persons.

-it permits the written document to become the reference in the absence of an instructor.

In brief, the protocol is an instrument similar to the armed forces SOP (standard operation procedure) which can be given to both the trained and untrained student alike.

\section{Audit Network}

This methodology involves several persons, groups, experts, physically distant from one another, who choose a single problem for study and solution. The audit concept is a continual monitoring of how people in different locations handle the given problem. Thus a problem is chosen; criteria for solving the problem are agreed upon; records are kept on problem cases; reviews, evaluations, and seminars are held to either improve the procedure or drop it entirely. The audit network is essentially a review mechanism, both by inside and outside experts, which seeks to maintain high quality results in several locations.

\section{Self-Teaching Cassette}

While this methodology is not new, it is included to suggest the variations which the medical field employs. Most often the approach is to simply videotape a lecture, by an expert, which students then insert into a video machine. A variation is the two-person presentation, one supporting a proposition, the other refuting it. Then follow with class discussion.

Additionally, role playing scenes are put on videotape; the student observes, draws conclusions, and offers his comments to the class.

Or, a series of questions, in hand-out form, are prepared to go along with the videotape presentation. The student records his answers as based on the tape and submits them to his instructor.

\section{Disputation}

Students of classical and Renaissance rhetoric will immediately recognize this ancient term to mean the art of debating, verbal controversy. A suggested procedure is the following:

-confront the student with a concept or theory that he can think about, forcing a yes or no response.

-study an example in depth, searching out a rule, an idea, a principle or a generalization which underlies the concept.

- experiment, actually or symbolically, gathering data to support or refute the student derived generalization.

-defend the final generalization; locate applications beyond the original example.

Student involvement can be organized by signing students up in advance to some position they will support on a stated proposition: for, against, let us say. Someone may be assigned the role of moderator. The end result, some claim, will be solutions which are founded on firm reasoning and testing.

\section{Instructional Design Team}

This team's approach is not unheard of, but has as one of its major purposes the reduction of conflicts after a new curriculum has been agreed to by a faculty. The thrust is upon weaving together resource persons who contribute to improved teaching within the new curriculum. In the nursing field at one major university, experts came from nursing practice; curriculum design; educational technology; instructional design; and evaluation procedures. Thus the practical aspects were agreed to prior to implementation of the revised curriculum.

\section{Guided Reading}

Most teachers today have not avoided problems associated with outside reading. The suggestion under the above heading is that a major effort must be placed on prior planning, seeking to answer three student questions: 
-Why this reading assignment? One could, for example, provide a series of questions to be answered by the readers as they move along, and state the purpose clearly at the start of every reading assignment.

-What to read for? Suggestions by the teacher as to what to skim over; what material related to the core of the course.

-How to read? Brief statement as to the importance of supporting materials, namely, examples, comparisons, contrast, and also evaluation of material.

Briefly, the method is to suggest in brief form the rationale behind the reading assignments, and then provide helps for the reader in relating the material to the core assignment.

\section{Peer Evaluation}

This interesting method permits students to be both student and supervisor, i.e., student $A$ will supervise student $B$, student $B$ will supervise student $\mathrm{C}$, and so on.

1. A running student supervisory log of suggestions is made of the observed student.

2 . The course teacher reads the log weekly and sends comments to supervisor and student.

3 . The class meets weekly for two hours, under direction of teacher, where problems and suggestions are discussed.

4. Both oral and written communication are extensively used.

The method appears to be workable inasmuch as both extensive checking and interpersonal communication occur between the student supervisor and the student, with close monitoring and feedback from the teacher.

\section{Telephone Lecture}

We include this method simply because the approach was an attempt to meet financial pressures of teaching persons in separate locations and in different organizations. Experts from several disciplines gave lectures via a telephone network: twenty minutes of lecture; thirty minutes of questionanswer. Prior to the lecture all centers received visual aids relating to the lecture, an outline of the lecture, and supplementary notes. Only a single concept was found to work satisfactorily over the 212 lectures and 21,000 participants.

\section{Behavioral Checklist}

Here is an attempt to measure students' ability to communicate well, interpersonally, in a clinical situation. A series of questions in eight areas formed the basis for the evaluation, as being either effective or ineffective:

Interaction
Questions
Listening
Observation
Problem Solving
Interpretation of the interaction
Evaluation of the interaction
Recording of the interaction

What gave more momentum to the methodology was that pre- and post-tests were administered to all students to determine the degree of improvement.

\section{Tape Recorded Evaluations}

This final methodology was most impressive in its positive results whereby all students received teacher feedback via their own individual sound cassette tape:

1. All students provided their own cassette tape.

2 . The teacher recorded daily observations and perceptions as correlated to course objectives.

3. Students played the tape at their own leisure and often recorded return comments back to their teacher.

4. All feedback was done on a weekly basis.

Reactions of students were favorable, many feeling they received positive reinforcement of their course activity.

\section{POSSIBLE INPUT FROM BUSINESS COMMUNICATORS}

While all the above teaching methodologies involve communication, either oral or written, it is clear that room exists for input from business communicators:

1. Methods for unambiguous writing of procedures for both the trained and untrained person.

2. Suggestions of clear written and oral communication techniques for groups studying a 
single problem.

3. Examples of well-phrased questions in response to videotape presentations.

4. Suggestions on the principles of oral debate, the use of evidence, reasoning, and illogical conclusions.

5. Essentials of a written abstract and supplementary handouts.

6. Requirements of the oral lecture: its need for clear communication and minimum inclusions.

\section{BIBLIOGRAPHY}

Judith Bancroft, "Instructional Design Team," Nursing Outlook, 1974, Vol. 11, No. 4, 254-257.

Irene Burnside, "Peer Supervision," Journal of Nursing
Education, November, 1971, Vol. 10, No. 3, 15-22.

Robert Davidson, et. al., "Audit Network," Hospitals, March 1, 1974, Vol. 48, 85-88.

Barbara Gallo and Donald Gallo, "Guided Reading," Journal of Nursing Education, January, 1975, Vol. 13, 21 . 25.

John Gallogher, et. al., "Telephone Lecture Network," Hospitals, January 16, 1975, Vol. 49, 65-66, 70.

Kenneth Kirk, "The Medium is as Important as the Message," Hospitals, July 16, 1974, Vol. 48, 67-70.

Helen F. McGrane, "Tape Recorded Evaluations," Journal of Nursing Education, January 1975, Vol. 14, No. 1, 11-17.

Donald Phillips, "Protocols for Patient Care," Hospitals, March 1, 1975, Vol. 8, No. 4, 29-34.

Margaret Topf, "A Behavioral Checklist for Estimating the Development of Communication Skills," Journal of Nursing Education, November, 1969, Vol. 8, No. 4, 29-34. Shirley Veith, "Disputation," Nursing Outlook, November, 1974, Vol. 22, No. 11, 699-701.

\title{
REVIEW OF LITERATURE FOR ABCA METHODOLOGY AND CONCEPTS COMMITTEE
}

\author{
Mary Jane Nelson \\ Central State University, Edmond, Oklahoma
}

The discussion which follows pertains to both written and oral communication as it applies to business. Areas of discussion are presented in the following order: (1) Oral/Speech Communication, (2) Nonverbal Communication, (3) Listening and Persuasion, and (4) Methods and Media for Teaching Communication. A complete bibliography will be provided upon request.

\section{ORAL/SPEECH COMMUNICATION}

Two problems seemed to dominate the literature which I surveyed: that of conducting effective meetings and of providing for effective upward communication within an organization.

In George H. Prince's article entitled "How to be a Better Meeting Chairman" (Harvard Business Review, Vol. 47, No. 1, p. 98), he suggests that the traditional style of chairmanship can destroy the creativity of small meetings. It develops an atmosphere of tension where participants don't feel free enough to contribute. A meeting leader needs to take greater advantage of his subordinates' capabilities and in so doing he can increase the achievement of the whole group. It is not an easy task to practice nonjudgmental leadership but it will pay off if you abide by his principal ground rules for this approach:

1. Never compete with group members. If you contribute any ideas you will unconsciously favor them. Give all members' ideas precedence over your own. The times when you may contribute are: (a) during an explanation at the beginning of a meeting, or during the solution phase at the end, and (b) after all other ideas have been explored.

2. Listen to the group members. Aim to understand. Rephrase their ideas to help be certain you actually do understand.

3. Don't permit anyone to be put on the defensive. Don't pressure anyone who wishes to remain silent.

4. Use every member of the group. Control compulsive talkers by avoiding eye contact or by looking at someone else and holding up your hand to the "talker" as a casual stop sign. Try to get the quiet ones involved but don't pressure them. Encourage them with your eyes.

5. Keep the energy level high. Your own interest, alertness, intensity are contagious. Use body movement. Keep meeting moving 